\title{
RESULTADOS DE LA ESTRATEGIA TERRITORIAL EN RED PARA LA INCLUSIÓN SOCIODIGITAL EN ANDALUCÍA ${ }^{1}$
}

\author{
Gustavo Antonio Contreras Cabrera \\ Departamento de Geografía Física y Análisis Geográfico Regional. Universidad de Sevilla \\ gcontreras@us.es
}

\section{RESUMEN}

En Andalucía se han producido crecientes impulsos correctores de la «brecha digital» desde la Administración Autonómica. Su análisis e interpretación centran este trabajo de investigación, tanto en el diseño estratégico emprendido, como en la impronta socioterritorial resultante.

Las conclusiones finales revelan deficiencias en la acción integradora de la Administración promotora, cuya corrección elevaría los niveles de eficacia o de equidad del servicio público prestado en beneficio de la población andaluza.

Palabras clave: Inclusión digital, estrategia, servicios públicos, territorio, red.

\begin{abstract}
Corrector pulses of the «digital divide» have been increasingly applied by the autonomic administration in Andalusia. The analysis and interpretation of this research focus, both in the strategic design undertaken, and the resulting socioterritorial imprint.

The final conclusions reveal some deficiencies in the integrative action of the promoting Administration, whose correction would increase the levels of efficiency or equity of the public service provided for the benefit of the Andalusian population.
\end{abstract}

Keywords: Digital inclusion, strategy, public services, territory, network.

Fecha de recepción: septiembre 2013.

Fecha de aceptación: junio 2014.

1 Este trabajo deriva del proyecto de tesis doctoral Las políticas de inclusión en la Sociedad de la Información en Andalucía: Planificación e impronta socioterritorial de la Red de Centros de Acceso Público a Internet (Programa Guadalinfo) y del análisis documental del Plan Estratégico Guadalinfo (2009-2012) 1levado a cabo durante una estancia en el Instituto de Desarrollo Regional, Fundación Universitaria, entre los años 2010 y 2012. 


\section{INTRODUCCIÓN}

Los progresos experimentados a finales del siglo XX en los dominios de la ciencia y la tecnología, unidos a una destacada explosión informativa vía redes telemáticas, han constituido la esencia de unas relaciones y compromisos sociales que llegan a alcanzar proporciones sin precedentes, y que han venido a denominarse, en términos generales, sociedad de la información. Un destacado ejemplo de los efectos que el proceso de inmersión sociodigital produce a escala internacional se observa en el fenómeno de la globalización, en sus diversas facetas (cultural, económico-financiera, política...), resaltando significativamente su impacto sobre estructuras tradicionales, como la organización del trabajo, las formas de gobierno o la gestión administrativa y territorial.

En coincidencia con este contexto, la ciudadanía andaluza ha protagonizado en los tres últimos decenios una progresiva incorporación a la sociedad de la información, mediante el uso y aprovechamiento de las tecnologías de la información y la comunicación (TIC), como queda reflejado en diversos estudios, estadísticas e informes consultados. Pero también, estas fuentes han revelado la existencia de importantes segmentos sociales desvinculados de las ventajas y oportunidades ofrecidas por dichas tecnologías. Ante ello, la Administración Autonómica andaluza impulsó en 2002 una iniciativa correctora de la brecha digital basada en la apertura experimental de 26 centros de acceso público a Internet en municipios caracterizados por su aislamiento geográfico y por reunir unas deficientes condiciones de desarrollo socioeconómico, cuyos resultados motivaron en 2004 la extensión progresiva de una red de equipamientos, -red Guadalinfo-, hasta cubrir en 2012 gran parte del territorio andaluz. Esta red se ha fundamentado en un programa de acciones de dinamización e inclusión sociodigital que alcanza su mayor grado de madurez con el impulso del Plan Estratégico Guadalinfo, diseñado para el periodo 2009-2012.

La investigación realizada entre 2010 y 2012 de las políticas públicas de inclusión en la sociedad de la información en Andalucía ha supuesto un reto de primer orden, justificando su diseño e impronta socioterritorial la apertura de nuevas vías de análisis para la Geografía. Como ya se ha señalado, la inequidad sociodigital está presente en el territorio de esta Comunidad Autónoma, así como las herramientas para combatirla. En consideración a esa dualidad, el trabajo aquí mostrado se centra especialmente en verificar la adecuación de la acción estratégica Guadalinfo, en su diseño y en la equidad territorial derivada de la implantación y funcionamiento de la citada red de centros de acceso y dinamización digital. A partir de la delimitación de unas hipótesis y objetivos iniciales, se realiza una identificación del marco teórico y metodológico de referencia, que da paso a la exposición de los principales resultados del estudio y a sus conclusiones finales.

\section{HIPÓTESIS Y OBJETIVOS INICIALES}

El examen del diseño e implementación territorial de la política de integración sociodigital que conforma la red de centros Guadalinfo toma como base de partida dos hipótesis vinculadas a un plan de trabajo cuya formulación se ha ajustado a otros tantos objetivos trazados. 
La primera hipótesis asigna a la experiencia Guadalinfo un diseño estratégico coherente con las políticas y estrategias impulsadas en el contexto político-administrativo y territorial en el que se integra la Comunidad Autónoma de Andalucía, aunque alejado de un diagnóstico de situación actualizado y orientativo de la agenda de planificación.

Un segundo supuesto indica que el proceso de implantación y desarrollo de esta red obedece a unas expectativas iniciales ya superadas, que no garantizan la equidad y los efectos distributivos en materia de inclusión sociodigital en el territorio andaluz.

Para un mejor desarrollo del estudio y verificación de las hipótesis planteadas es fijado como objetivo global la profundización en el conocimiento de la política de integración y dinamización sociodigital existente en Andalucía, impulsada a través de la red Guadalinfo y su acción inclusiva, y en desarrollo de esta meta genérica son propuestos los siguientes objetivos específicos:

1. Determinación de la racionalidad y la coherencia existentes en el diseño de la estrategia Guadalinfo. Esta meta toma como referencia el Plan Estratégico Guadalinfo 2009-2012, comprobando su idoneidad como respuesta a las circunstancias de la brecha digital detectada en Andalucía, asumiendo la filosofía de acción integradora de su entorno político y administrativo más inmediato, así como la adecuación de sus líneas de intervención a los objetivos que las sustentan.

2. Verificación de la equidad en el alcance socioterritorial de la red. Es decir, desvelando hasta qué punto la red de centros adscritos a la experiencia Guadalinfo presenta una distribución en el territorio andaluz adecuada a las necesidades de integración sociodigital. Para ello, son consideradas sus diferentes etapas de implantación, así como la población con necesidades de acceso a los centros en los municipios de esta Comunidad Autónoma.

Además de los resultados que se exponen, la validez de los supuestos de partida y el cumplimiento de los objetivos enunciados quedan contemplados en las conclusiones finales de este trabajo de investigación.

\section{MARCO TEÓRICO}

La investigación de la estrategia en red para la inclusión sociodigital en Andalucía tiene dos importantes soportes teóricos en la definición de las políticas de alfabetización y dinamización digital, concretamente en la calidad de su diseño, así como en la implementación de redes de centros vinculadas a un modelo de servicio público de acción positiva en el territorio. Ambos se encuentran ligados al principio de equidad y a los efectos distributivos de unas estrategias públicas que canalizan la acción reductora de la brecha digital vía planificación.

El ejercicio de alfabetización y dinamización digital representa una parte esencial en las políticas dirigidas a mitigar aquellos desequilibrios socioterritoriales relacionados con la plena integración individual y colectiva en la sociedad civil global (Mattelart, A. 2007). De hecho, su diseño e implementación constituyen el eje principal de ataque a la denominada pantalla de restricciones: 


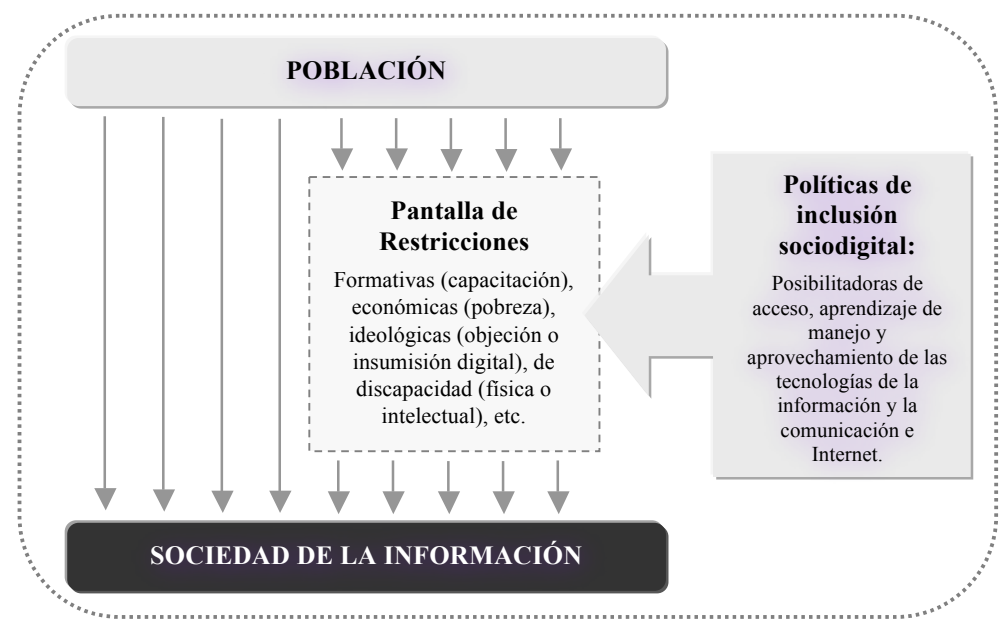

Fuente: elaboración propia.

En este sentido, cabe reconocer la existencia de importantes esfuerzos públicos y privados facilitadores de un acceso ciudadano efectivo a las TIC en el territorio como fórmula eficaz defendida por diversos investigadores e instituciones para superar las citadas restricciones (Castells, M. 2006). Sin embargo, otras líneas de estudio condicionan la validez de la puesta a disposición de estos recursos como parte constitutiva de impulsos de inclusión más amplios que conviene identificar (Boza, A. y otros, 2010). Este planteamiento se basa en la idea de que la brecha digital tiene su origen en causas diversas y complejas, a modo de desequilibrio digital multidimensional (Van Winden, W., 2003), que requieren respuestas integradoras y persistentes relacionadas en gran medida con el desarrollo de aptitudes ciudadanas, como las políticas educativas de corte universal. Así, la alfabetización y dinamización digital representan un enfoque capacitador, en general, planificable y ligado a la adquisición de habilidades y conocimientos propios de un individuo o colectividad cívicamente competente (Selwyn, N., 2004).

La canalización de las políticas de integración sociodigital por parte de la Administración Pública, acometida mediante instrumentos de planificación, permite su estudio y valoración bajo el enfoque de la optimización de su diseño (Noguera, J. y otros, 2009). De hecho, existen importantes avances teóricos y metodológicos centrados en la excelencia del diseño estratégico, acorde con una lógica preestablecida de adecuación a los problemas y necesidades existentes (escenario inicial o de partida) ${ }^{2}$, la concordancia con un ambiente estratégico externo de metas similares, o la idoneidad de sus objetivos y líneas de acción con el escenario de futuro esbozado (Contreras, G. A., 2012).

2 Existen diversas interpretaciones sobre de la forma de afrontar la planificación o el diseño estratégico, en base al conocimiento de la naturaleza de los problemas a resolver, como el modelo de Hisschemöller-Hoppe identificativo de relaciones entre la estructuración de un problema y las estrategias públicas desde un punto de vista cognitivo (Subirats, J. y otros, 2012), que otorga relevancia al reconocimiento de un escenario de referencia para el diseño del plan de integración sociodigital por parte de los agentes promotores. 
Esta opción de diseño expuesta encuentra un significativo referente en el Enfoque del Marco Lógico (EML), desarrollado a finales de 1960 a partir de experiencias internacionales en materia de cooperación para el desarrollo ${ }^{3}$. De hecho, son realizadas importantes aportaciones desde grupos de trabajo como el dirigido por C. Haugland en el seno de la Agencia Noruega de Cooperación para el Desarrollo (NORAD, 1993), cuyos conceptos más destacados pueden apreciarse en la Figura 2, adaptada a las condiciones de diseño y características del Plan Estratégico Guadalinfo:

Figura 2

ESQUEMA CONCEPTUAL DEL EML

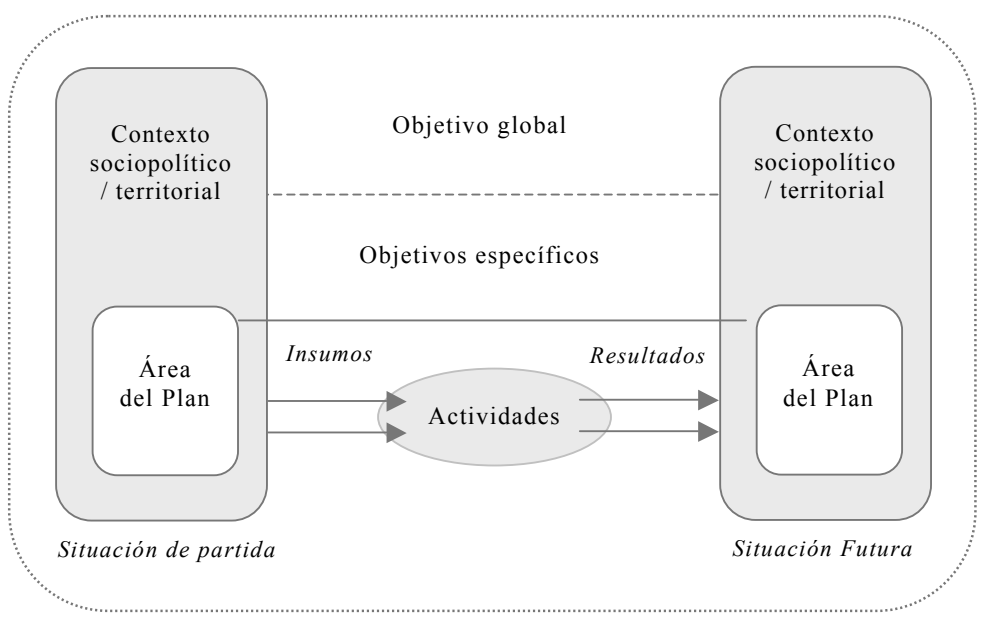

Fuente: elaboración propia, a partir de la NORAD (1993).

Las argumentaciones teóricas basadas en el EML quedan dispuestas en forma de cadena secuencial de búsqueda de la calidad planificadora orientada mediante objetivos que tiene en cuenta la existencia de factores externos (acelerantes o distorsionadores) y de precondiciones. Así, partiendo de la disponibilidad de recursos necesarios se prevé la realización de las actividades anunciadas; si éstas se realizan, entonces se producirán resultados; si se producen resultados, se logrará el objetivo específico; y a largo plazo, esto contribuirá al cumplimiento de la meta global.

Estas consideraciones, tienen una especial relevancia al constituir un sólido soporte y complemento, a la vez, para la evaluación de políticas como la que centra esta investigación, facilitando la toma de decisiones y juzgando entre distintas alternativas, todo ello con la idea de permitir acciones como la revisión de objetivos, costes y beneficios previstos (Stufflebean, D. L., 1987; Lindblom, C. E., 1991; Noguera, J. y otros, 2009). Así mismo, se observa en la evaluación de políticas públicas la oportunidad de aprendizaje o formación, mejorando el conocimiento de los agentes implicados en sus propias decisiones para una mejor admi-

3 Organismos dedicados a la cooperación internacional o al fomento del desarrollo socioeconómico, como la Agencia Estadounidense para el Desarrollo Internacional - US AID, la Organización para la Cooperación y el Desarrollo Económico - OCDE o la Dirección General para el Desarrollo (D.G.VIII) de la Unión Europea. 
nistración, gestión o adaptación a las necesidades del momento y del contexto (Scriven, M., 1967 y 1980). En este caso, interesa destacar la denominada evaluación conceptual o de diseño, modalidad orientada a valorar la calidad del plan estratégico en cuestión, de acuerdo con los elementos que justifican su necesidad y la forma en que éste se articula. Se trata de un enfoque evaluador que afronta la planificación de forma holística, integrando la valoración desde el primer momento de la intervención pública y que mantiene en el esquema conceptual del Marco Lógico un respaldo excepcional e inmediato (Osuna, J.L. y Márquez, C., 2002) $)^{4}$.

Por otra parte, se aprecian modelos e interpretaciones teóricas concernientes a la inclusión sociodigital que toman como figura de referencia los propios centros de apoyo comunitario al acceso, alfabetización y dinamización digital. Un conjunto de equipamientos que, diseñado desde una óptica de trabajo en red, actúa como servicio especializado en la atención de necesidades específicas y corrección de la desigualdad, permitiendo incluso su universalización como complemento válido a otras políticas de bienestar social (Tarroja, À. y Camagni, R., 2006). Estos centros operan incluso como instrumentos visibles de la acción compensatoria que la alfabetización-dinamización digital posee (Servon, L. J. y Pinkett, R. D., 2006), en un contexto movilizador y/o educativo gratuito e informal (Casado, R., 2006) que admite diversos cometidos en la búsqueda de la equidad social y territorial, desde el libre acceso a las TIC e Internet, hasta el acercamiento ciudadano a las TIC dentro de un proceso integral de inmersión en la sociedad de la información que incluye la dinamización de usos y competencias.

La planificación de estas redes y la disposición espacial de sus centros puede responder, desde un punto de vista cognitivo, a la asunción de un escenario de partida o diagnóstico previo que identifique problemas a solventar, necesidades a cubrir y potencialidades, evitando así nuevas situaciones de inequidad motivadas por la implantación territorial inadecuada de este tipo de red de atención ciudadana. Ello posibilita concretar unos objetivos y líneas de actuación acordes con las características de la población destinataria y su localización geográfica, y con las de los recursos a movilizar (Subirats, J., 2012). Igualmente, se aprecia la eventualidad de fijar un modelo de servicio sujeto a una doble condición, según su estructura organizativa y según su contenido y población beneficiaria, que fundamente la construcción de una red prestadora de servicios de carácter personal o universal (Tarroja, À. y Camagni, R., 2006), llegando incluso a captar e implementar estrategias innovadoras de marcada adecuación a la finalidad de justicia distributiva que las origina (Ferrero, F. y De la Cuesta, G. A., 2007).

Con arreglo a estos aportes, queda puesta de manifiesto la dificultad de conciliar una única base teórica en torno a los diferentes tipos o criterios de búsqueda de la justicia social, siguiendo los clásicos modelos descriptivos o metodológicos de planificación espacial de los servicios públicos (Pitarch, M. D., 2000), en este caso centrada en la equidad sociodigital. Otra opción consistiría en definir la topología de red más idónea para su logro a la hora de actuar en el territorio, -según los diferentes planteamientos de estructura y funciones del

4 Planificación y evaluación: una visión integral. Interpretación que ha tenido una especial relevancia en el desempeño investigador de organismos como el Instituto de Desarrollo Regional, fundación universitaria (Universidad de Sevilla) y su posterior difusión de resultados. Frente al modelo lineal de incorporación de la evaluación al final del ciclo de las políticas, la perspectiva integral la incorpora en todas sus fases, incluyendo su diseño. 
espacio geográfico (Higueras, A. M., 2003)-, basados en variables como el coste, la equidad social y locacional o la demanda del servicio. Dicha circunstancia es especialmente significativa cuando las condiciones de igualdad y de equilibrio interterritorial se encuentran sometidas a continuos cambios y ajustes que dependen, en muchos casos, del denominado contexto o ambiente del plan (NORAD, 1993), como es la interrelación existente entre la intervención correctora, las causas de la brecha y las propias capacidades de disposición territorial de la red. En el caso de la intervención correctora, son considerables aspectos esenciales en el ciclo de vida de una política pública relacionados con la percepción de los problemas y necesidades presentes, la inclusión en la agenda gubernamental o la implementación de planes de acción (Subirats, J., 2012).

\section{METODOLOGÍA APLICADA}

En sintonía con las hipótesis, objetivos y soportes teóricos contemplados inicialmente, la metodología de investigación seguida en este trabajo se agrupa en dos bloques analíticos bien definidos, referidos a la cobertura en el diseño estratégico de inclusión sociodigital emprendido desde la Administración Autonómica Andaluza y a la determinación del alcance socioterritorial de la red Guadalinfo:

- Por una parte, el análisis del diseño estratégico se inicia con un examen pormenorizado de la figura emblemática que rige la acción integradora de la Administración Autonómica en Andalucía: el Plan Estratégico Guadalinfo 2009-2012. Dicha labor se sustenta en el mencionado enfoque teórico y metodológico del Marco Lógico, vinculado a la evaluación conceptual o de diseño estratégico de políticas, planes o programas $^{5}$, ambos basados en un modelo de acción por objetivos, en línea con una adecuada identificación de las necesidades y problemas que representa la brecha sociodigital en esta comunidad autónoma. En este caso, la unidad de análisis considerada coincide con la propia figura del Plan Guadalinfo, interesando su contenido, estructura y programación. Así, la relación de causalidad que establece el EML en su esquema general de aplicación resulta ser la fuente de referencia para la evaluación mencionada, afianzando la posibilidad de plantear preguntas fundamentales y valorar las debilidades existentes.

Al inicio de esta investigación (año 2010) la implementación del Plan Guadalinfo era ya un hecho consumado, por ello, se consideró esencial acometer un examen de su grado de racionalidad y coherencia, revisando los elementos y circunstancias que justificaban su necesidad y estrategia aplicada en el citado ámbito territorial. Concretamente, se puso a prueba su relevancia (aptitud del diagnóstico realizado al esce-

5 Entendiendo que la planificación y la evaluación son procesos relacionados que caminan a la par, la validación del Plan ha seguido las directrices de varios agentes clave expertos en la línea de evaluación de políticas públicas y de gestores de la red de centros de acceso público a Internet consultados. Concretamente, se han considerado entre sus apreciaciones la disponibilidad de un diagnóstico de partida indicador de las condiciones de inequidad digital existentes, la fijación de objetivos y líneas de actuación que respondan a los problemas y/o necesidades detectados, y la posibilidad de verificar su compatibilidad con el marco estratégico de lucha contra la brecha digital en el que se integra la acción andaluza Guadalinfo (España y la Unión Europea). 
nario de partida), su pertinencia (calidad de la definición de sus diferentes objetivos, general y secundarios), y la concordancia interna (línea lógica de causalidad entre diagnóstico, objetivos, estrategias y acciones operativas del Plan) y externa (planificación o estrategias del entorno) de acuerdo con el contexto político-administrativo y estratégico al cual se encuentra vinculada la Comunidad Autónoma Andaluza.

- Por otra parte, la determinación del alcance socioterritorial de la estrategia en red Guadalinfo fija su acción en el cálculo de la impronta que ésta ha tenido sobre la población y el territorio. Para ello, son examinados el perfil identificativo de la población objetivo y la lógica de su cobertura socioterritorial. Estos componentes se desarrollan en niveles o escalas territoriales diversos con el fin de construir una imagen inequívoca de la citada impronta (sus referentes geográficos de valoración son la región, la provincia, la comarca y el municipio), todo ello de acuerdo con los atributos de implantación de dicha red y con la evolución de los condicionantes que originaron su impulso.

En concreto, es afrontada la suficiencia de cobertura de los centros de acceso público a internet a la población con necesidades de acceso y aprovechamiento de estos recursos TIC conforme al despliegue realizado de esta red en Andalucía, a partir de las necesidades y aspiraciones sociales y de la distribución geográfica de la población objetivo.

En suma al enfoque multiescalar de la investigación, se plantea un análisis comparativo entre territorios avanzados o dinámicos, bajo un punto de vista del desarrollo socioeconómico, y otros territorios que la propia Administración Autonómica ha calificado como a revitalizar, constituyendo un estudio de caso basado en el empleo de ocho comarcas-testigo (Figura 3). De este modo, se intenta comprobar la coherencia del modelo de cobertura de la red Guadalinfo, ligando las diferentes necesidades de uso de los centros de integración sociodigital a las condiciones socioeconómicas detectadas en los territorios donde éstos prestan servicio.

La selección territorial expuesta toma como referencia dos comarcalizaciones diferentes de reconocida validez en distintos foros institucionales y de investigación. Así, los territorios a revitalizar han sido extraídos de la zonificación andaluza correspondiente al Programa de Desarrollo Rural Sostenible (PDRS) 2010-2014, surgido al amparo de la Ley 45/2007, de 13 de diciembre, para el desarrollo sostenible del medio rural. Entre las acciones de revitalización previstas en este Programa destaca la reducción de desequilibrios en materia de tecnologías de la información y la comunicación. Como contraposición, los ámbitos comarcales dinámicos se han seleccionado a partir de la clasificación territorial llevada a cabo por el grupo de investigación de Estudios Andaluces GEA XXI (Cano, G., 2001 y 2003).

Junto a la segmentación básica que la Administración de la Junta de Andalucía establece entre los municipios beneficiarios de la red Guadalinfo ${ }^{6}$, ha sido considerada la existencia de municipios con población superior a 20.000 habitantes cuya dotación de centros de atención sociodigital (centros de acceso público a Internet o CAPI) queda limitada a determinadas

6 Un centro asignado a cada municipio menor de 10.000 habitantes y la posterior ampliación de cobertura a municipios menores de 20.000 habitantes (convocatoria de incentivos mediante Orden de 7 de octubre de 2008, Consejería de Innovación, Ciencia y Empresa - Junta de Andalucía). 
barriadas desfavorecidas, seleccionadas por la presencia de colectivos ciudadanos en situación de exclusión social (minorías étnicas, inmigrantes extranjeros, bolsas de pobreza o altos niveles de desempleo) en estrecha relación con la exclusión digital. Estos casos han sido tratados a escala municipal, integrados en las comarcas mencionadas e incluidos en la categoría de ámbitos con cobertura parcial de esta red.

Figura 3

REPARTO TIPOLÓGICO DE COMARCASAANALIZAR

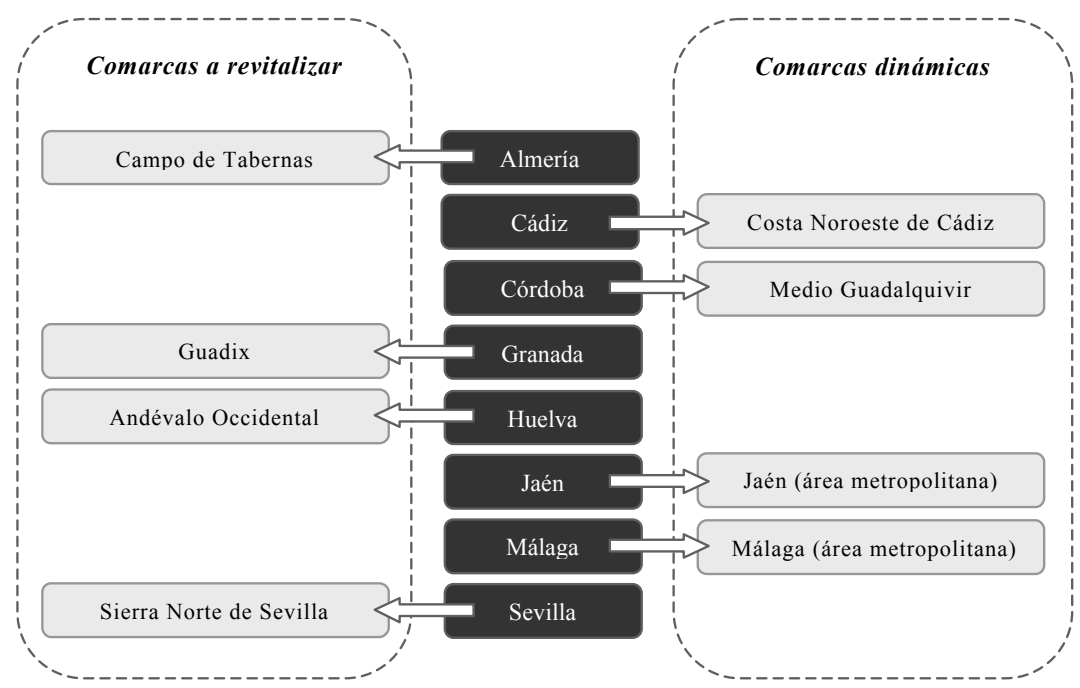

Fuente: elaboración propia.

Así pues, la distinción interterritorial se ha realizado en base a varios niveles temáticos, destacando aquellos relacionados con la disponibilidad de centros de acceso público a Internet, determinando la existencia de vacíos dotacionales (totales o parciales), con el tamaño poblacional de los municipios, o con su nivel de desarrollo socioeconómico, cuyo interés reside en la comprobación de la vigencia de los planteamientos iniciales de implantación de la red.

Las fuentes de información empleadas en este trabajo han sido básicamente bibliográficas o documentales y estadísticas (directas e indirectas). En el primer caso, cabe resaltar la escasa documentación editada y disponible acerca de la política regional de inclusión sociodigital, circunstancia que ha derivado en la prospección de fuentes vinculadas directamente con la planificación, la gestión y regulación de procedimientos o el desarrollo estratégico ejecutivo, destacando sobremanera aquellos documentos de planificación e informes de gestión y resultados que muestran el desarrollo de las políticas integradoras desde su origen, o bien asociados a un momento concreto o periodo temporal determinado. Se trata de información proveniente en su mayoría de la Administración, en niveles tan variados como la Unión Europea, el Estado Español o las Comunidades Autónomas, y especialmente la andaluza. 
De igual modo, las fuentes estadísticas han resultado de gran valor para la investigación, especialmente las directas que surgen como parte indiscutible del propio plan de trabajo diseñado. La principal fuente estadística directa ha consistido en un sondeo de opinión dirigido a la población residente en los ocho territorios sujetos a estudio de caso. Éste se ha desarrollado a través de mil entrevistas personales que han tenido como soporte técnico un cuestionario diseñado a tal efecto ${ }^{7}$, intentando determinar el perfil de la población con necesidades de acceso y aprovechamiento de los centros de la red Guadalinfo y la lógica de su alcance socioterritorial.

Junto a los contenidos documentales disponibles para la evaluación del diseño del Plan Estratégico Guadalinfo, la recopilación de suficiente información relevante relativa a la impronta socioterritorial de la red de centros ha permitido el adecuado tratamiento y análisis (estadístico y cartográfico), desglosando según temáticas y ámbitos geográficos de valoración, para una posterior interpretación de resultados y fijación de conclusiones que son mostrados a continuación.

\section{EVALUACIÓN DE LOS RESULTADOS ALCANZADOS}

Tras la exposición de aspectos metodológicos relevantes para esta investigación, procede mostrar y valorar sus resultados más destacados, considerando en todo momento la trayectoria de esta experiencia pública de inclusión social planificada que se ha venido ajustando a las cambiantes condiciones y recursos del contexto operativo en el que se enmarca la Comunidad Autónoma de Andalucía. Dicho encuadre incluye las políticas de apertura a la sociedad de la información desde la Europa del Conocimiento invocada en el seno de la UE (1997) en base a estímulos activos a la adquisición de conocimientos y competencias, de personas y empresas, que transforman la sociedad de la información emergente en una sociedad del saber (Mattelart, A., 2007), hasta los impulsos llevados a cabo por sus estados Miembros, siguiendo el principio de subsidiariedad en el desarrollo de estas estrategias Comunitarias.

Junto al examen del diseño e impronta socioterritorial de la red de centros Guadalinfo, conviene destacar que su configuración obedece a una evolución de las políticas correctoras de la divisoria digital en Andalucía implementada en los niveles normativo, estratégico y territorial:

- El nivel normativo ha prestado cobertura jurídica al proceso de inclusión sociodigital en Andalucía, revelando en su evolución desde el año 2002 su ajuste a un modelo de actuación y gestión basado en la centralización del control organizativo y financiero por parte de la Administración Autonómica. En esencia, se aprecia un sistema regulador de incentivos periódicos orientado a garantizar unas condiciones de homogeneidad en el funcionamiento de la red. Del mismo modo, ha fijado las reglas de cooperación con diversas instituciones colaboradoras, públicas o privadas, y establece categorías territoriales para los centros de acceso público a Internet, según población,

7 Las 1.000 entrevistas realizadas han sido precedidas por 648 intentos nulos y 70 parcialmente nulos (ambos casos desechados). La distribución final de éstas se ha ajustado proporcionalmente al tamaño poblacional de las comarcas seleccionadas en el estudio de caso. 
en municipios menores de 20.000 habitantes (grupos A, B y C) ${ }^{8}$; según barriadas desfavorecidas o zonas en riesgo de exclusión social (CAPI); y en comunidades andaluzas en el exterior (CAE), presentes en otras comunidades autónomas españolas o en el extranjero.

- Estratégicamente, se ha podido identificar un proceso de inclusión sociodigital vinculado a las diferentes figuras de planificación impulsadas por la Administración Autonómica en Andalucía, desde el Programa Regional de Acciones Innovadoras -PRAI Guadalinfo- (2002), hasta el Plan Estratégico Guadalinfo (2009-2012). Este proceso se ha caracterizado por un sostenido crecimiento de los recursos y servicios ofrecidos a la población.

- Desde el punto de vista territorial, la red Guadalinfo ha sido objeto de un desarrollo muy destacado que se inicia en 2002, con la apertura experimental de 26 centros de atención ciudadana ubicados en una selección de municipios pertenecientes a las ocho provincias andaluzas. La constatación de resultados positivos en la reducción de la brecha digital trajo consigo una extensión progresiva a partir del año 2004 hasta la actualidad $^{9}$ (Mapa 1):

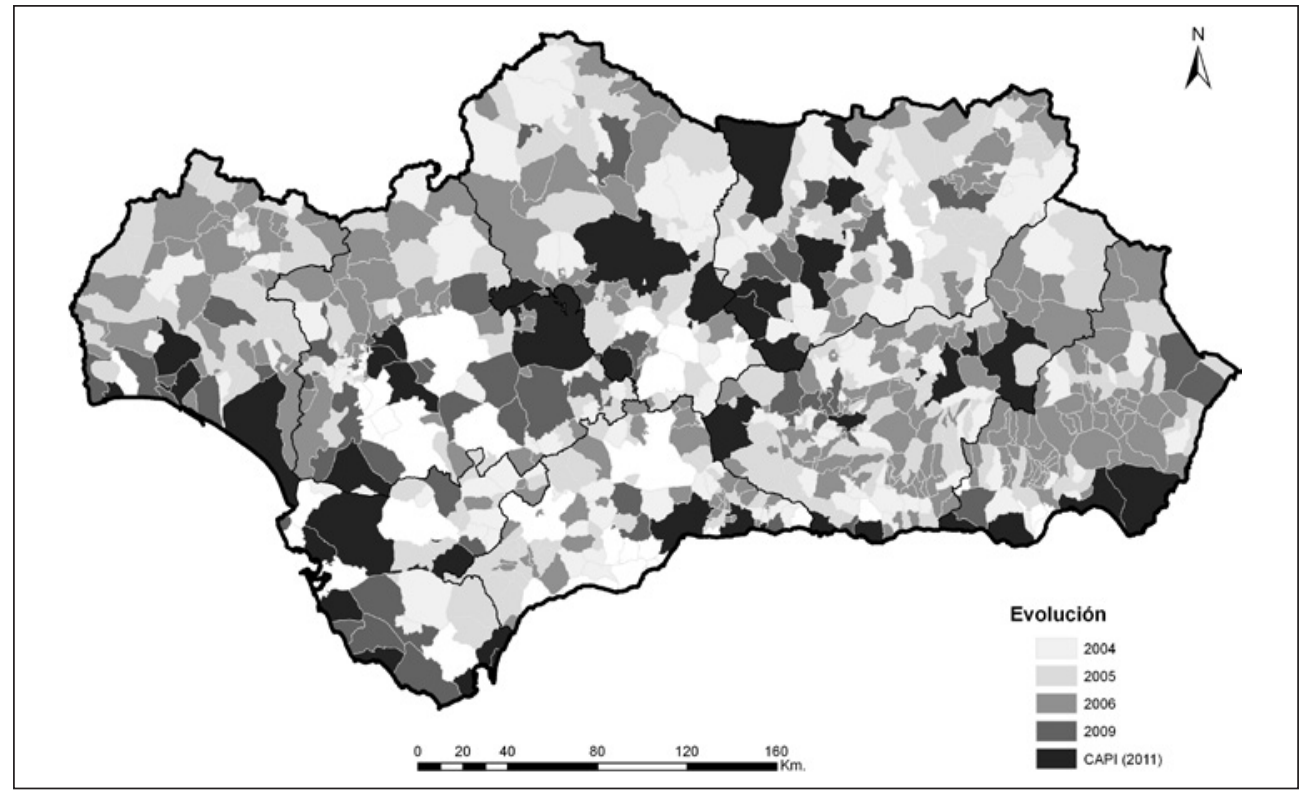

Fuente: elaboración propia.

8 Municipios de 0 a 1.000 habitantes (grupo A); municipios de 1.001 a 10.000 habitantes (grupo B) y municipios de 10.001 a 20.000 habitantes (grupo C).

9 Para los centros de acceso público a Internet (CAPI) ubicados en barriadas desfavorecidas sólo se expresa el año de la última programación (2011). Así mismo, los centros pertenecientes a las Comunidades Andaluzas en el Exterior (CAE) quedan excluidos de esta investigación. 
No obstante, la limitada implantación de esta red en el territorio ha mantenido notables vacíos de cobertura en varias decenas de municipios que son valorados a partir del análisis de la inequidad socioterritorial existente.

\section{V.1. Diseño estratégico de las acciones de inclusión sociodigital}

A partir del análisis efectuado al diseño estratégico de la red Guadalinfo se han obtenido resultados de especial trascendencia para un mejor conocimiento de su estructura organizativa y gestora, así como de la adecuación de los objetivos y actuaciones del Plan Estratégico Guadalinfo al escenario de inequidad sociodigital existente en Andalucía. Además, dicha labor ha permitido identificar las condiciones y principios rectores de su implementación en el territorio.

En especial, la evaluación desarrollada ha incidido en la estructura organizativa y de gestión del Plan (mapa de actores implicados), así como en la racionalidad y la coherencia de su diseño, tomando como referencia el Enfoque del Marco Lógico de planificación orientada mediante objetivos.

\section{V.1.1. Mapa de actores clave}

El mapa de actores contemplados en su gestión y funcionamiento posee gran fortaleza estructurante y organizativa, aunque en él se precia una asignación de roles que parece no responder adecuadamente al modelo organizativo que requiere esta extensa red de centros, por el desproporcionado peso decisorio y rector de la Administración Autonómica y de las Diputaciones provinciales frente al papel claramente subordinado de los actores colaboradores (ayuntamientos y entidades ciudadanas sin ánimo de lucro):

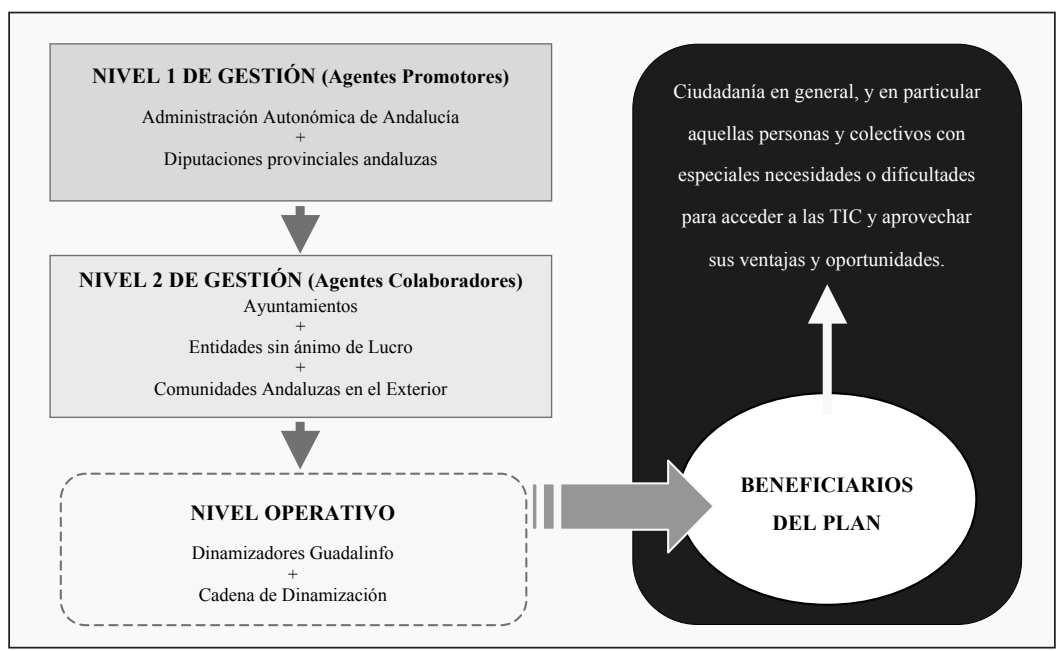

Fuente: elaboración propia. 
Ha resultado especialmente significativa la inequidad decisoria de los ayuntamientos andaluces, Administración cuya capacidad operativa en la red se reduce, básicamente, a la aportación de determinados medios materiales (inmueble donde se ubica el centro) y a la selección-contratación de agentes dinamizadores (con cargo a los incentivos regulados para la creación y mantenimiento de estos equipamientos). Por tanto, el análisis de las capacidades y competencias de estas entidades locales ha traído como resultado más destacado el escaso aprovechamiento de determinadas potencialidades, como un mejor seguimiento y coordinación entre sus agentes y los dinamizadores de los centros, además de optimizar el diseño estratégico de líneas de actuación (globales o específicas) a través de los encuentros periódicos de coordinación que se celebran.

En línea con estas consideraciones, se ha apreciado la posibilidad de encajar la participación de estas entidades locales en el Consorcio gestor de la estrategia Guadalinfo (Consorcio Fernando de los Ríos $)^{10}$ y la sustitución de su actual condición de destinatarios de incentivos periódicos para la creación y funcionamiento de centros por medio de convenios de colaboración impulsores de actuaciones conjuntas de inclusión sociodigital.

Del mismo modo, ha sido analizada la participación de entidades colaboradoras en barriadas desfavorecidas y en ámbitos referidos a comunidades andaluzas en el exterior. Al tratarse de entidades sin ánimo de lucro de carácter asociativo y con fines muy diversos se ha podido apreciar una doble circunstancia que pone en riesgo la estabilidad y eficacia de la acción integradora en los ámbitos beneficiarios. Por un lado, no se garantiza un enfoque integral de la intervención frente a la brecha digital, dada la existencia de sesgos importantes relacionados con el objeto de actuación de cada entidad asociativa (lucha contra la drogadicción, integración social de minorías étnicas o inmigrantes, igualdad de género, acción frente a la pobreza y el desempleo, etc.). En otros casos, se ha percibido insolidez en la gestión, fruto de las decisiones y desempeños particulares de sus órganos directivos y/o debido a la variabilidad de los recursos disponibles.

El mapa de actores queda completado en su nivel operativo por los agentes dinamizadores existentes en cada centro de la red, constituyendo una importante masa técnica en contacto directo con los usuarios y con sus necesidades y aspiraciones. Para el desempeño de su labor cotidiana se constata el respaldo de la denominada «cadena de dinamización», conformada en cada centro por una serie de usuarios motores o personas con mayores capacidades de convocatoria pública, en su mayoría representantes del movimiento asociativo local y técnicos de administraciones públicas como la Local, actuando como enlaces de los centros con sus respectivos ámbitos de influencia.

Tras el análisis de este sistema operativo se han puesto de manifiesto una serie de carencias en torno al modelo participativo de los usuarios en la planificación de las actividades o contenidos del servicio de los centros. En gran medida, la fluidez informativa y de participación existente en las cadenas de dinamización marca diferencias entre los territorios analizados, concretándose en su globalidad la aspiración de los usuarios a un modelo de gobernanza definida por una mayor implicación ciudadana en el seguimiento y diseño de líneas de acción y la efectividad en la difusión del servicio prestado a través de los centros de acceso público a Internet.

10 El Consorcio Fernando de los Ríos está participado por la Administración de la Junta de Andalucía y las ocho Diputaciones provinciales andaluzas (2007), contando con el Consejo Rector como órgano de gobierno y administración y con una Comisión Ejecutiva (órgano de trabajo delegado del Consejo Rector). 


\section{V.1.2. Examen de la racionalidad y la coherencia del Plan}

Al afrontar la evaluación correspondiente al diseño del Plan Estratégico Guadalinfo, es preciso referir su vinculación con otra figura de planificación de rango superior: el Plan Andalucía Sociedad de la Información (ASI) 2007-2010. Esta circunstancia es tenida en cuenta en su análisis, tanto en el de racionalidad, como en el de coherencia, al existir importantes nexos entre el impulso de la sociedad de la información que esa figura promueve en Andalucía y la acción correctora de la inclusión sociodigital que el Plan Guadalinfo contempla como parte fundamental en dicho proceso.

Entrando directamente en la valoración del Plan Guadalinfo 2009-2012, para hacer efectivo su examen se ha seguido un esquema de referencia que profundiza en los elementos básicos del análisis de racionalidad, la relevancia y la pertinencia, y en los de la coherencia, en sus modalidades externa e interna (Figura 6):

- En un principio, la relevancia representa el grado de adecuación del diagnóstico realizado a la situación real de inequidad sociodigital existente en Andalucía. Dependiendo de la calidad de visualización de los problemas, necesidades y potencialidades de superación de la citada inequidad por parte de los planificadores, mediante un diagnóstico válido, se fijarán objetivos estratégicos apropiados, a modo de respuesta lógica, permitiendo un grado suficiente de pertinencia en el Plan diseñado.

- Del mismo modo, es entendida la coherencia de esta figura estratégica regional, tanto en la cadena de implementación que se desprende de los objetivos estratégicos (coherencia interna), como en su compatibilidad o complementariedad con otros planes o figuras estratégicas del contexto operativo donde se inserta la política andaluza de corrección de la brecha digital (coherencia externa).

Figura 5

ESQUEMA DE IMPLEMENTACIÓN DEL ANÁLISIS DE DISEÑO ESTRATÉGICO DEL PLAN

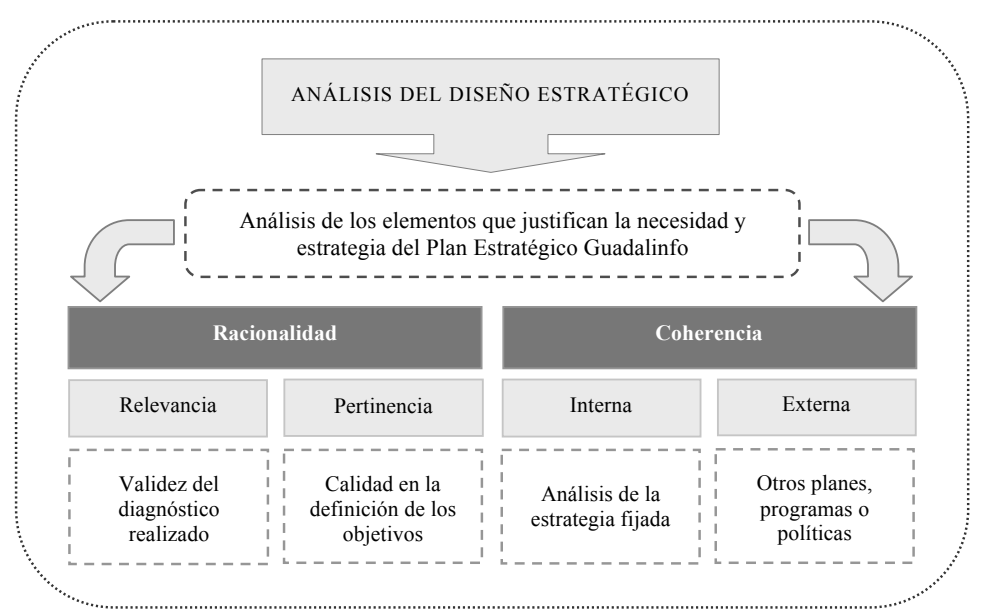

Fuente: elaboración propia. 
Comenzando por el examen de la racionalidad, cabe indicar que el Plan carece de relevancia en su diseño, al no ofrecer un diagnóstico de situación que oriente la estrategia a seguir. Su diseño parece responder a las inercias de la labor emprendida desde el año 2002 en materia de integración sociodigital, así como a sus vínculos con otras figuras de planificación de su contexto operativo, cuyo principal referente es el Plan ASI 2017-2010. Aun pudiendo existir entre sus redactores una conciencia global de las necesidades y potencialidades de la red, reflejada en las propuestas de actuación que se formulan, no se logra justificar la falta de un escenario inicial a transformar que aporte solidez a la argumentación de objetivos y acciones desplegados.

Por otra parte, el análisis de pertinencia ha permitido valorar la calidad y grado de adecuación en los objetivos trazados, resultando una importante debilidad motivada por la falta de claridad y de concreción en algunos de los compromisos asumidos y en sus planteamientos estratégicos. De hecho, no es presentada una meta global única, sino que se aprecia solapamiento entre varias intenciones expresadas. Además, los objetivos estratégicos marcados adolecen de claridad y concreción en sus planteamientos. Por último, es destacada la falta de logros medibles derivados de dichos compromisos, confirmando que el Plan carece de un desarrollo explicativo que puntualice resultados concretos basados en la secuencia ¿qué se pretende?, ¿para qué? y ¿cómo conseguirlo?

En cuanto a la coherencia analizada, en su faceta interna se detecta un importante salto argumental entre los objetivos y las estrategias de actuación diseñadas. Esta cuestión resulta especialmente preocupante dada la ausencia de un escenario de partida que marque las necesidades a transformar. En concreto, se puede confirmar la ruptura de la articulación en cascada de su acción estratégica, advirtiéndose la necesidad de completar la definición de una meta sólida que permita implementar la consolidación de un modelo de gestión basado en la excelencia. Dicho inconveniente dificulta la sostenibilidad del proyecto o la mejora continua en su desarrollo, mediante fórmulas que contemplan desde el fomento de buenas prácticas, hasta la corresponsabilidad de los agentes participantes y la autoevaluación a aplicar.

Por contra, al examinar su coherencia externa se ha comprobado un alineamiento acorde con los intereses y retos del marco operativo en que se desarrolla. Esta condición se confirma tras haberse verificado suficiente compatibilidad del Plan Estratégico Guadalinfo, en sus objetivos y acciones estratégicas, con los de las siguientes escalas geográfico-administrativas y figuras estratégicas:

- Unión Europea: Iniciativa i2010 para la Inclusión Digital.

- Estado Español: Plan AVANZA I (2005-2010).

- Comunidad Autónoma de Andalucía: Plan ASI (2007-2010).

Otro aspecto examinado, en consonancia con la metodología del Marco Lógico, es el referido a la determinación de aquellos factores del contexto externo con posibilidad de interferir, positiva o negativamente, en el desarrollo de las actuaciones diseñadas en el Plan. Tras una detallada comprobación se confirma que dichos factores han sido omitidos en su diseño, aun existiendo circunstancias altamente significativas para la eficacia, la eficiencia y la equidad de Guadalinfo, como la intensificación de la crisis económico-financiera y 
alteración de las condiciones socioeconómicas en los municipios andaluces, el incremento de personas en riesgo de exclusión social, la existencia de realidades alternativas de gestión en el ámbito territorial de la Administración Local, como mancomunidades, asociaciones o consorcios, o la presencia de experiencias paralelas de integración con capacidad de interferencia en la red de centros.

\section{V.2. Alcance socioterritorial de la experiencia Guadalinfo}

Mediante el análisis del alcance socioterritorial se ha respondido al doble reto de verificar la equidad en la distribución de la red de centros de acceso público a Internet en el territorio andaluz, además de su adecuación y composición en relación con la población potencialmente beneficiaria de su estrategia de establecimiento y funcionamiento. Para el esclarecimiento de estas consideraciones se ha emprendido un examen del perfil identificativo de la población objetivo (real y potencial) y de la lógica seguida en la implantación de los centros vinculados a dicha red.

El conocimiento obtenido a través del acercamiento y tratamiento informativo de estos apartados ha resultado realmente valioso, tanto en su aporte cuantitativo, como en las valoraciones cualitativas alcanzadas. Para ello, se ha combinado la información procedente de las entidades responsables de implantar y gestionar los centros de acceso público a Internet con las contribuciones de las entrevistas realizadas a la ciudadanía de las ocho zonas objeto de estudio de caso.

\section{V.2.1. Perfil de la población objetivo}

Para acometer el análisis de caracterización de la población diana de esta acción integradora, además de incidir en aspectos generales como el sexo o la edad, se ha profundizado en los rasgos asociados al riesgo de exclusión, como la situación laboral, el nivel formativo, la nacionalidad o la posible discapacidad. Así mismo, se ha procedido a la identificación de aquellas personas con carencias reales de acceso y manejo de las TIC, además de quienes han manifestado tener aspiraciones de integración en la sociedad de la información.

Los resultados más destacados coinciden con importantes mermas de acceso y manejo de las TIC e Internet vinculadas en gran medida a la falta de medios económicos, de conocimientos para su uso y de tiempo disponible. Estas carencias, agrupadas en niveles nulo/ muy bajo y bajo de acceso y manejo, se han concentrado principalmente en personas de nacionalidad española, mayores de 25 años, sin estudios o con estudios primarios (completos e incompletos), con predominio de las mujeres como sexo más afectado. No obstante, se ha observado que la situación laboral de estas personas no es determinante, al existir un reparto igualado entre personas ocupadas, desempleadas y jubiladas/pensionistas, levemente superior en el primer grupo.

A su vez, cabe añadir que dichas insuficiencias se han mostrado en directa proporción con las elevadas aspiraciones de los entrevistados al uso y aprovechamiento de las TIC, constatándose una fuerte convicción colectiva de superación de esta adversidad.

Atendiendo a la doble tipología de comarcas testigo seleccionadas en este estudio, resultan casi idénticas las necesidades de acceso y manejo de las TIC e Internet y las pretensiones 
de salvar dichas restricciones, tanto en comarcas más dinámicas como en aquellas a revitalizar. Este descubrimiento permite constatar que la brecha digital se encuentra presente en el conjunto de la Comunidad Autónoma andaluza, sin que exista una especial vinculación con las diferencias globales de desarrollo socioeconómico interterritorial. Más bien, parece asociarse a determinadas concreciones, como el bajo nivel de instrucción de un $67 \%$ de la población sondeada que dificulta la asimilación de innovaciones tecnológicas asociadas a la sociedad de la información.

Otro resultado alcanzado mediante la caracterización de la población objetivo ha sido el reducido nivel de conocimiento de los entrevistados acerca de la realidad Guadalinfo, en directa proporción con su reconocida condición de usuarios (Gráfico 1):

\section{Gráfico 1}

\section{RECONOCIMIENTO DE LA EXPERIENCIA GUADALINFO \\ Y DE LA CONDICIÓN DE USUARIOS DE CENTRO}

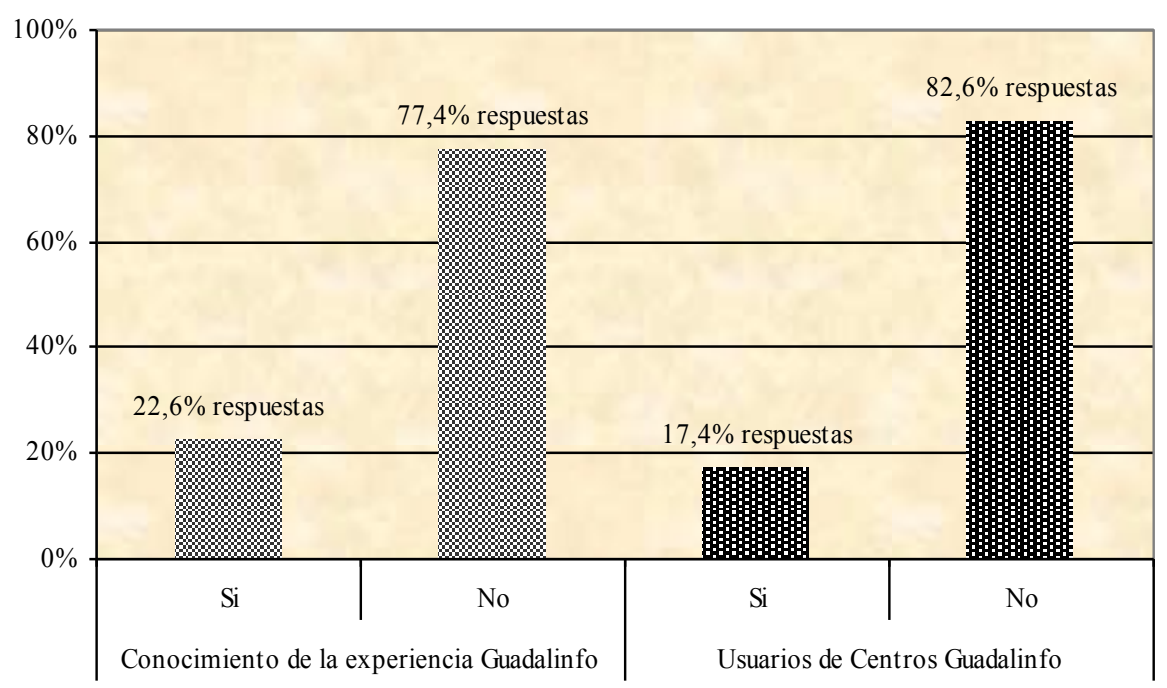

Fuente: elaboración propia.

Las respuestas emitidas han evidenciado fallos en el modelo de gestión de la información/comunicación acerca de los servicios prestados, así como de las ventajas y potencialidades propias de esta red de centros, también confirmados por los entrevistados.

\section{V.2.2. Lógica de la correspondencia socioterritorial}

Fruto del análisis realizado, tendente a desentrañar la vigencia de los argumentos que conformaron inicialmente esta red, se han conseguido resultados especialmente categóricos, confirmando cambios que invitan a la revisión. Esto no anula los criterios que activaron su implantación en el territorio andaluz, sino más bien resalta nuevas necesidades y perspectivas detectadas como consecuencia de la transformación experimentada en el 
escenario socioeconómico y tecnológico de la comunidad autónoma. El estudio efectuado se ha basado en dos consideraciones importantes:

- Por un lado, se ha reparado en el proceso de implantación seguido tras la exitosa experiencia piloto del PRAI Guadalinfo en municipios menores de 20.000 habitantes (año 2002). Esencialmente, se produjo un cambio de criterio que llevó a su extensión progresiva (2004-2006) a 637 municipios menores de 10.000 habitantes, junto a la apertura en 2007 de 26 nuevos centros en barriadas o zonas urbanas desfavorecidas o en riesgo de exclusión social. A partir de 2009, se detecta una nueva ampliación de la red con 56 nuevos centros en municipios de entre 10.000 y 20.000 habitantes.

- Aparte de esta dinámica evolutiva, se han identificado algunas razones que originaron la implantación de la red Guadalinfo en Andalucía, como el déficit de acceso a Internet de banda ancha en determinados municipios, la disparidad de recursos económicos municipales para contrarrestar la exclusión sociodigital y la existencia de extensas áreas rurales y espacios urbanos con escaso nivel de desarrollo socioeconómico y riesgo de exclusión social.

Atendiendo a estas circunstancias, se ha comprobado un importante avance entre 2003 y $2010^{11}$, en los municipios con menor población (hasta 10.000 habitantes), pasando su disponibilidad de líneas ADSL (línea de abonado digital asimétrica) de un 37,18\% inicial a un $96,12 \%$ del total de estas entidades. Incluso la proporción de habitantes por cada línea ADSL experimenta en estos municipios un destacado descenso (de 84,45 habitantes por línea ADSL en 2003 baja a 8,41 habitantes por línea en 2010). Este cambio supera las mejoras registradas en municipios mayores de 10.000 habitantes,

A su vez, la insuficiencia de medios municipales para impulsar políticas o estrategias reductoras de la brecha digital en aquellas entidades con menor población ha sido examinada vía gasto municipal por habitantes llevado a cabo por sus respectivas administraciones locales. De este modo, se ha podido confirmar un incremento generalizado del presupuesto general de gastos entre 2003 y 2010, más acentuado en ayuntamientos de municipios menores de 10.000 habitantes que en otros de mayor rango. Esa circunstancia sugiere una solvencia global de los ayuntamientos pequeños para afrontar la divisoria digital, especialmente en las provincias de Cádiz, Jaén o Sevilla, lejos de su aparente debilidad inversora.

Por último, la implantación de centros basada en el carácter aislado y el reducido desarrollo socioeconómico de municipios menos poblados, así como el riesgo efectivo de exclusión existente en zonas de grandes núcleos urbanos, entra en contradicción con la nueva propuesta de territorios (agrupaciones de municipios) con necesidades de revitalización socioeconómica efectuada por la propia Administración Autonómica, en el marco del Programa de Desarrollo Rural Sostenible (2010-2014) ${ }^{12}$. Esta nueva zonificación, per se, reduciría el

11 Estos años de referencia coinciden con el momento previo a los convenios interadministrativos para la implantación de la red Guadalinfo (2003) y la última disposición vigente para el mantenimiento de dichos centros (2010).

12 Las 11 zonas consideradas a revitalizar en Andalucía y contenidas en el PDRS 2010-2014 poseen unas condiciones de inequidad, calculadas y actuales, que permiten la localización concreta en el conjunto territorial andaluz de este déficit socioeconómico detectado. Y en este sentido, la extensión de la red de centros de acceso 
número de municipios con presencia de centros de la red Guadalinfo (733 entidades) a un $42,7 \%$. En cuanto a los núcleos con centros ubicados en barriadas desfavorecidas o zonas declaradas en riesgo de exclusión, éstos han experimentado una constante variación por creación o eliminación de dichos centros, en parte sujeta a las condiciones y requerimientos de las diferentes convocatorias de incentivos destinados a la creación/mantenimiento de los centros, y también debido a las capacidades gestoras de las entidades asociativas (agentes colaboradores) que operan en dichos ámbitos.

\section{V.3. Relación de proporcionalidad entre la población objetivo y la oferta de centros}

El Análisis de la proporcionalidad existente entre la población objetivo y la oferta real de centros de la red Guadalinfo se ha desarrollado a través de ratios de beneficiarios (efectivos y potenciales) por centro implantado en las ocho comarcas seleccionadas para el estudio comparativo de casos, identificando además posibles vacíos socioterritoriales (totales y parciales) en el conjunto territorial andaluz. En este caso, se han llegado a descubrir severas diferencias interterritoriales, de acuerdo con el poblamiento, las necesidades de integración sociodigital expresadas y la distribución geográfica de los centros, siempre en perjuicio de las cuatro comarcas más dinámicas.

\section{V.3.1. Proporcionalidad de la red}

Los territorios con mayor desarrollo socioeconómico han presentado ratios de carencias ciudadanas más abultadas en torno a las TIC e Internet por cada centro existente, respecto de aquellos considerados a revitalizar (ratios 1 y 2). Esta situación se reproduce con las capacidades de manejo de dichas tecnologías y con la actitud mostrada hacia una plena integración en la sociedad de la información (ratios 3 y 4), como se aprecia en el gráfico 2.

Por otra parte, se ha detectado una diferencia global significativa entre las ratios anteriores y la correspondiente al número de los usuarios registrados de la red Guadalinfo en estos territorios por cada centro de acceso público a Internet existente (ratio 5), circunstancia especialmente destacada en las comarcas más desarrolladas, cuya desventaja con las comarcas a revitalizar es demostrativa de la inequidad socioterritorial que ha supuesto la distribución de centros en base a los criterios iniciales de localización.

Queda así expuesto el potencial de cobertura de la red, confirmando además la oportunidad de incrementar las acciones de prospección, difusión y captación de nuevos usuarios, o bien de generar nuevos recursos allí donde existen claras insuficiencias de estos equipamientos y sus servicios de inclusión.

\footnotetext{
público a Internet impulsada por la Administración Autonómica da cobertura casi completa a los municipios incluidos en dicha zonificación (99,68\% de los casos). No obstante, se trata de una cobertura relativa, basada en la presencia de un centro de acceso público a Internet por municipio, sin reparar en su capacidad para dar servicio efectivo a toda la población potencialmente beneficiaria o en la existencia de obstáculos a la plena accesibilidad de sus usuarios.
} 


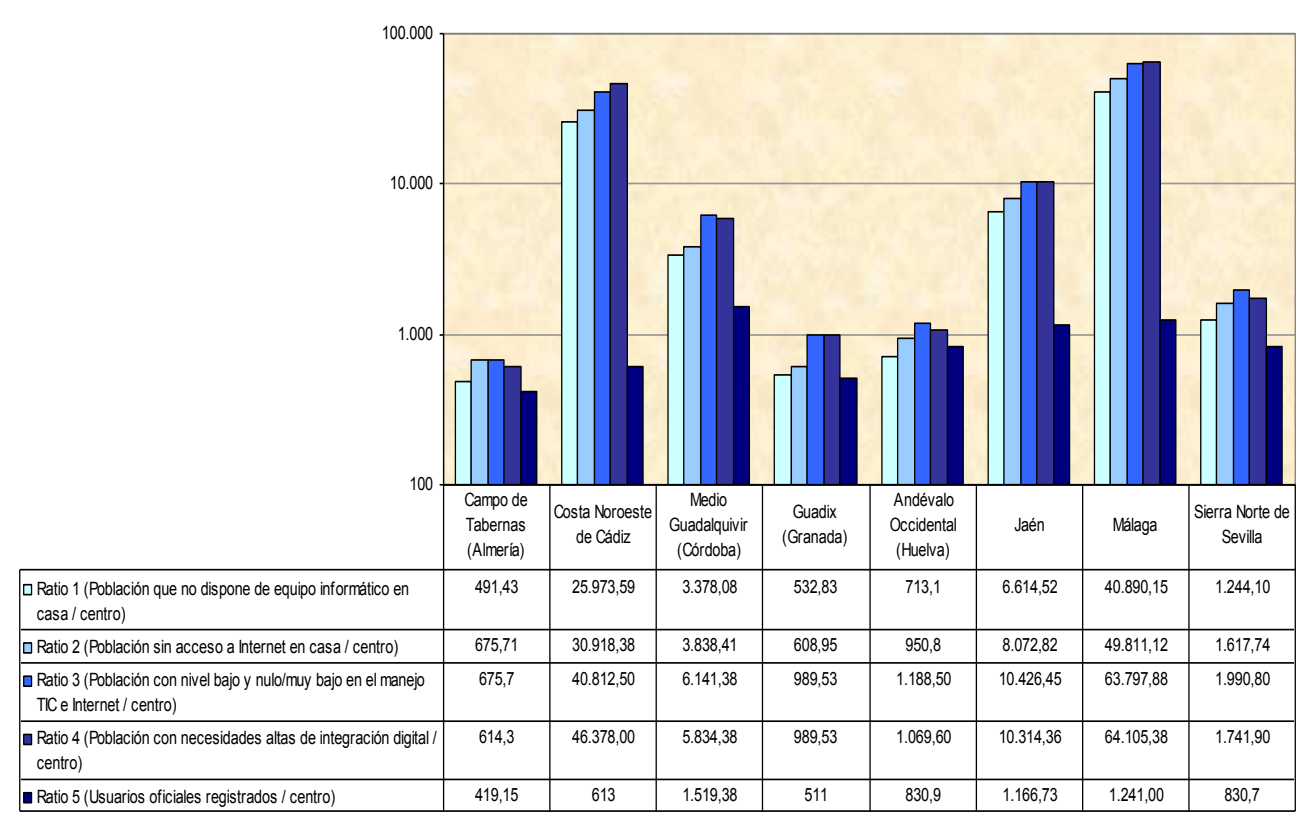

Fuente: elaboración propia.

\section{V.3.2. Vacíos territoriales detectados}

Tras analizar la presencia de la red Guadalinfo a escala municipal se ha constatado la existencia de 37 municipios carentes de centros de acceso y dinamización sociodigital. Esta circunstancia es especialmente significativa si se considera que en dichos municipios reside el 20,14\% de la población andaluza (casi 1.700.000 habitantes, según datos padronales de 2010).

El resultado anterior se agrava al incluir vacíos territoriales parciales, de acuerdo con la distribución de centros efectuada en determinadas barriadas desfavorecidas de 64 grandes municipios y ciudades (Mapa 1). En este caso, no se ofrece necesariamente cobertura a la totalidad de la población de los municipios donde se encuentran implantados dichos centros, sino que ésta se circunscribe a las zonas urbanas seleccionadas, mayormente por su vinculación a proyectos dirigidos a segmentos muy específicos de población (minorías étnicas, personas con problemas de drogadicción, inmigrantes, etc.), hecho que limita el acceso al conjunto de residentes con necesidades de inclusión.

Junto a las causas regladas ${ }^{13}$ que determinan la existencia de vacíos de cobertura, como pueden ser el tamaño poblacional de los municipios o la presencia de bolsas de exclusión

13 Diferentes disposiciones normativas reguladoras y convocantes de incentivos destinados a la creación y mantenimiento de centros de acceso público a Internet contemplan diversas condiciones acerca de su finalidad y posibles beneficiarios, designando incluso las barriadas desfavorecidas objeto de intervención. 
social, se han detectado otras razones relacionadas con la ausencia de entidades colaboradoras pertenecientes al movimiento asociativo con actitud y capacidad suficiente para implantar y mantener un centro de acceso público a Internet o el cese de incentivos a la nueva creación de este tipo de equipamiento desde 2010 en las convocatorias públicas efectuadas.

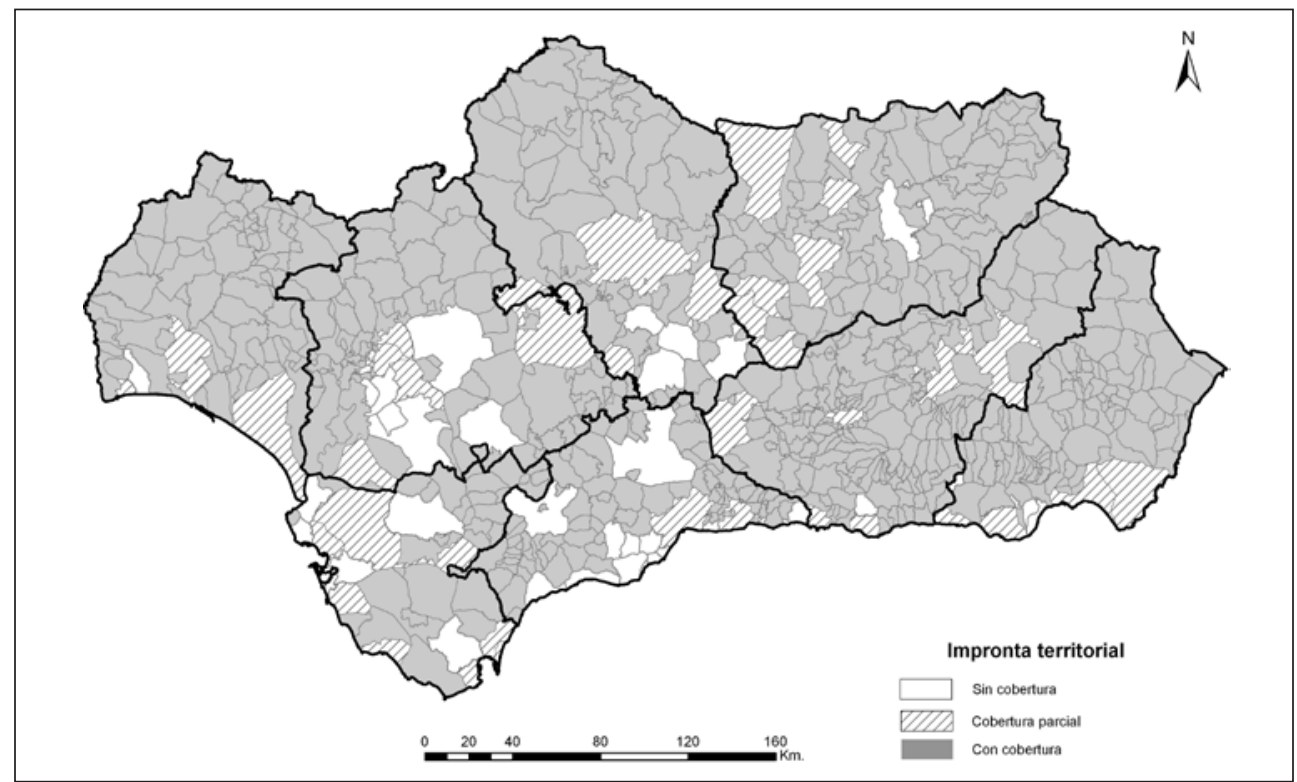

Fuente: elaboración propia.

Centrando estas apreciaciones en la muestra de comarcas objeto de estudio de caso, son mayoritarias las carencias dotacionales en los cuatro ámbitos más desarrollados, verificándose así una inequidad socioterritorial en la cobertura de la red Guadalinfo que contrasta con las necesidades y posibilidades de prestación existentes.

\section{CONCLUSIONES}

El examen e interpretación de las políticas de inclusión sociodigital emprendidas en Andalucía por parte de la Administración Autonómica han propiciado diversas apreciaciones de cierre del proceso de investigación desarrollado. En este sentido, son mostradas algunas conclusiones, con el objeto de recapitular sobre los resultados alcanzados, tanto con carácter general, como referidas a los puntos específicos examinados.

En su globalidad, el presente estudio ha venido ligado a una constante aspiración de avance en los conocimientos teóricos existentes en torno al fenómeno de la inequidad sociodigital surgida en paralelo al desarrollo de la sociedad de la información, así como en las fórmulas correctoras impulsadas por los poderes públicos mediante de redes territoriales 
de contención. Si bien existe un cuerpo teórico e interpretativo extenso respecto del concepto sociedad de la información, así como de la brecha digital, apenas se han identificado estudios en profundidad centrados en el diseño y puesta en práctica de políticas públicas de integración sociodigital, incluyendo las estrategias y métodos más adecuados para atajar las inequidades surgidas. Es en el diseño de pautas e instrumentos válidos y su puesta en práctica donde se han apreciado los mayores vacíos exploratorios y explicativos sobre resultados conseguidos e impactos demostrables en la población beneficiaria. De este modo, resulta especialmente útil la aportación de esta investigación a la construcción de un marco teórico, metodológico y de contextualización al respecto, admitiendo su aprovechamiento como referente abierto y revisable desde la Geografía y otras disciplinas vinculadas preferentemente con la Ciencia Regional.

La exploración de aspectos concretos en Andalucía, relacionados con el diseño estratégico de las acciones de inclusión sociodigital y con la expresión socioterritorial de la red Guadalinfo, ha permitido profundizar en el conocimiento y comprensión de la configuración de esta red, sus principales carencias, principalmente metodológicas en la planificación y en la gestión, así como aquellas posibilidades de mejorar la equidad de sus acciones sobre una población beneficiaria (real y potencial) distribuida en el territorio de esta comunidad autónoma, cuyas características y necesidades responden a nuevos escenarios, dinámicos en su expresión espacial y temporal, y marcados por los avances socioeconómicos y tecnológicos que se vienen sucediendo.

Si bien, la planificación de la experiencia Guadalinfo responde a unos criterios de calidad globalmente aceptables, resulta excepcional la falta de un diagnóstico de base que aporte certidumbre al diseño de metas y estrategias de integración sociodigital, además de cuidar la ausencia de saltos e inconsistencias en la cadena causal que conforma el esquema ideal de planificación adoptado en este estudio, de acuerdo con el enfoque seguido del Marco Lógico. Estas consideraciones se relacionan también con la construcción de un mapa de actores (gestores) que proporciona la visualización de diferentes niveles de gestión, a pesar de constatarse la idoneidad de asegurar mayores cotas de colaboración y coordinación mediante relaciones institucionales más igualitarias. Del mismo modo, se aprecia la necesidad de aportar solidez a la red en barriadas y zonas desfavorecidas, excesivamente dependiente de las actitudes y capacidades del conjunto de entidades sin ánimo de lucro que colaboran en la gestión de centros.

Tras un examen pormenorizado, se ha verificado la existencia de convergencia entre los objetivos y acciones estratégicas puestos en práctica en las escalas político-territoriales de la Unión Europea, España y Andalucía, propiciando una movilización coherente de recursos y en convergencia contra la brecha digital en dichos niveles de intervención.

Confirmada la falta de vigencia de las consideraciones iniciales de implantación de la experiencia Guadalinfo, resulta paradójico que las ciudades y municipios con población superior a 20.000 habitantes limiten su cobertura de centros a barriadas o zonas consideradas como desfavorecidas, que responden a una realidad o caracterización de marginalidad social paralela o desencadenante de la exclusión digital detectada. Esta circunstancia no encuentra un cuerpo justificativo claro que diferencie o excluya del servicio público al conjunto de su población, dadas las carencias o aspiraciones de acceso y aprovechamiento de las TIC e Internet puestas de manifiesto a través del sondeo de opinión efectuado. 
Así mismo, el empleo de un método de comprobación de la inequidad distributiva de esta red integradora, -basado en la comparación de ratios de cobertura territorial-, ha demostrado la existencia de vacíos de prestación y de importantes déficits de asistencia pública a la ciudadanía, independientemente de la dinámica o riqueza socioeconómica de cada territorio, de los recursos públicos municipales o del tamaño poblacional de los núcleos urbanos. Ahondando en el nuevo escenario de necesidades y potencialidades detectadas, se ha observado un aumento general de usuarios en aquellas zonas declaradas a revitalizar por la propia Administración, cuestión que acentúa las diferencias existentes con los territorios restantes. En otros casos, ha resultado llamativa la presencia de importantes bolsas de beneficiarios potenciales, no usuarios de esta red, en grandes municipios y ciudades cuya cobertura es parcial o nula. Estas incidencias desvirtúan la acción positiva emprendida, aconsejando una reflexión estratégica y metodológica acerca del diseño y funcionalidad de la realidad Guadalinfo.

Los resultados y conclusiones expresados corroboran la validez de las hipótesis de partida formuladas en esta investigación, dada la positiva coherencia de esta red en su diseño con el contexto estratégico externo, en contraste con la falta de conexión de sus objetivos y líneas estratégicas con unos problemas y necesidades bien definidos. Así mismo, se verifica la prescripción de unas razones de implantación superadas por nuevas realidades e inequidades. En cuanto a la orientación de este estudio, cabe confirmar el cumplimiento del propósito principal que ha guiado su implementación, al haber progresado en el conocimiento de los impulsos públicos en materia de integración sociodigital llevados a cabo en Andalucía. Este objetivo se ha conseguido mediante la interpretación del proceso estratégico y territorial de configuración de la red de centros y la comprobación de la desigualdad resultante de su implementación en el territorio, especialmente en los déficits de cobertura que frenan una mayor y mejor inclusión socioterritorial en la sociedad de la información.

\section{REFERENCIAS}

ALBURQUERQUE, F. (1997): El proceso de construcción social del territorio para el desarrollo económico local. Santiago de Chile. ILPES/CEPAL.

BALLESTERO, F. (2002): La brecha digital: El riesgo de exclusión en la sociedad de la información. Madrid. Fundación Retevisión.

BOZA, A. y OTROS (2010): Educación, investigación y desarrollo social. Madrid. Nancea S.A. de Ediciones.

CANO, G.M. (Dir.) (2001): Una propuesta de comarcalización para Andalucía. Pueblos, Ciudades y Comarcas Andaluzas. Sevilla. Tartessos.

CANO, G.M., Dir. (2003): Conocer Andalucía: Gran Enciclopedia Andaluza del siglo XXI. Sevilla. Tartessos.

CASADO, R., (Coord.) (2006): Claves de la Alfabetización Digital. Madrid. ARIEL - Fundación Telefónica.

CASTAÑO, C. y ROMÁN, C. (Coords.) (2002): Andalucía ante la sociedad de la información. Sevilla. Consejo Económico y Social de Andalucía.

CASTELLS, M. (2006): La sociedad red: una visión global. Madrid. Alianza Editorial.

CONTRERAS, G. (2012): «Asociacionismo en red para la integración sociodigital en Andalucía». Revista de Estudios Andaluces, n 29, 103-124. 
ESPARCIA, J. y PANIAGUA, (2006): «Políticas Públicas, Sustentabilidad y Geografía Rural. Una Agenda de Estudio». Boletín de la Asociación de Geógrafos Españoles, $\mathrm{n}^{\circ}$ 41, 3-10.

FERRERO, F. y DE LA CUESTA, G.A. (2007): Libro Blanco de Buenas Prácticas para el despliegue de redes inalámbricas de banda ancha en municipios de Andalucía. Sevilla. Consejería de Innovación, Ciencia y Empresa (Junta de Andalucía).

GARCÍA, I. (2005): «Políticas para la inclusión social mediante tecnologías de la información y la comunicación». Revista Electrónica Teoría de la Educación: Educación y Cultura en la Sociedad de la Información, Vol. VI, $\mathrm{n}^{\circ}$ 1. Universidad de Salamanca. Disponible en http://campus.usal.es/ teoriaeducacion/rev_numero_06/n6_art_garcia_ iolanda.htm

HERNÁDEZ, M. (Coord.) (2008): Exclusión social y desigualdad. Murcia. Ediciones de la Universidad de Murcia.

HIGUERAS, A.M. (2003): Teoría y método de la Geografía. Introducción al análisis geográfico regional. Zaragoza. Prensas Universitarias de Zaragoza.

JORDÁ, R. y LUCENDO, A.L. (2002): «Escenarios para una estadística sobre Innovación de dimensión regional. Su aplicación en Andalucía». Economía Industrial $\mathrm{n}^{\circ}$ 344, pp. 177-190.

LINDBLOM, C.E. (1991): El proceso de elaboración de las políticas públicas. Madrid. INAP.

MATTELART, A. (2007): Historia de la sociedad de la información. Barcelona. Paidós.

NOGUERA, J. y OTROS (2009): Gestión y promoción del desarrollo local. Valencia. Publicaciones de la Universidad de Valencia.

NORAD (1993): El enfoque del marco lógico: Manual para la planificación de proyectos orientada mediante objetivos. Madrid. Instituto Universitario de Desarrollo y Cooperación. UCM-CEDEAL.

OSUNA, J.L. y MÁRQUEZ, C. (Coords.) (2002): Guía para la Evaluación de Políticas Públicas. Sevilla. IDR, Fundación Universitaria.

PITARCH, M.D. (2000): «Los modelos de planificación espacial de los servicios públicos: El caso de los servicios educativos». Cuadernos de Geografía, n 67-68, 119-136.

ROBLES, J.M. (2005): La Sociedad de la Información en Andalucía. Sevilla. Junta de Andalucía.

SELWYN, N. (2004): Literature Review in Citizenship, Technology and Learning. Bristol. Futurelab.

SERVON, L.J. y PINKETT, R.D. (2006): «Estrechando la brecha digital: potencial y límites del movimiento de tecnología comunitario norteamericano» en La sociedad red: una visión global (Castells, M., Ed.). Madrid. Alianza Editorial, 390-412.

SCRIVEN, M. (1967): «The methodology of evaluation». En Perspectives of Curriculum Evaluation (Tyler, R. W., Gagne, R. M. y Scriven, M., eds.). Chicago. Rand McNally and Company, 39-83.

SCRIVEN, M. (1980): The logic of evaluation. Inverness, Ca. Edgepress.

SERRANO, A. y MARTÍNEZ, E. (2003): La brecha digital. Mitos y realidades. Baja California. Departamento Editorial Universitaria de la Universidad Autónoma de Baja California. 
STUFFLEBEAM, D.L. (1987): Evaluación de contexto, entrada, proceso y producto. Barcelona. Paidos.

SUBIRATS, J. y OTROS (2012): Análisis y gestión de políticas públicas. Barcelona. Ariel.

TARROJA, A. y CAMAGNI, R. (2006): Una nueva cultura del territorio. Criterios sociales y ambientales en las políticas y el gobierno del territorio. Barcelona. Diputación de Barcelona.

TRAVIESO, J.L. y PLANELLA, J. (2008): «La alfabetización digital como factor de inclusión social: una mirada crítica». UOC papers. Revista sobre la Sociedad del Conocimiento, $\mathrm{n}^{\circ} 6$, miscelánea, 1-9.

TRINIDAD. A. (2010): Análisis y evaluación de políticas sociales. Madrid. Tecnos.

VAN WINDEN, W. (2003): Essays on urban ICT policies. Rotterdam. Tinbergen Institute. Erasmus University Rotterdam. 
